\title{
Systematic Incident Command Training and Organisational Competence
}

\begin{abstract}
Aim: To determine if the application of a systematic command training system (Effective Command) could influence the organisational competency profile, through the identification, training, and assessment of key behavioural markers.

Design/methodology/approach: The Effective Command framework is aligned to UK National Fire Service role-maps and is routinely used in both development and assessment of Fire Officers worldwide. Data from 1261 formal assessments was analysed and descriptive statistics performed.
\end{abstract}

Findings: Structured analysis of incident command assessment data should inform subsequent training cycles of individuals, organisations, and procedures. Key Behavioural Markers were identified in Level 1 (L1) and Level 2 (L2) commanders which influence assessment outcomes. Reduced competence scores between $\mathrm{L} 1$ and $\mathrm{L} 2$ officers were recorded, providing a strong argument for a supported development process for $L 2$ officers.

Practical implications: Six key behavioural markers were identified in L1 commanders, all were associated with information comprehension and evaluation, which ultimately impacted the outcomes of formal assessments. This study provides empirical evidence that frequent incident or scenario exposure, coupled with metacognitive understanding of the decision rationale could reverse these weaknesses and turn them into individual strengths. This in-depth analysis of data generated in individuals who pass or fail these assessments should strengthen organisational learning.

Originality/value: The use of a structured command training framework contributes significantly to operational assurance by providing a robust assessment and training methodology, which ensures that organisations can appoint, train, and assess their Incident Commanders.

\section{Introduction}

The operational landscape and responsibilities of International Fire Services have changed dramatically over the last fifteen years, with terrorist attacks (Deeming, 2018), extreme weather events and complex fire prevention strategies, all greatly affecting the scope, severity and, importantly, numbers of incidents attended (Home Office, 2019). This dynamic operating landscape challenges fire services to implement change, adapt, innovate, and evolve to maintain service levels commensurate with community risk. These challenges are further complicated by efficiency savings, resource reductions and additional non-operational responsibilities (FBU, 2015), increasing the demand for efficient and effective operational training that allows personnel to train for the unexpected. 
Systematic Incident Command training and Organisational Competency.

Fire Officers are required to be technically proficient and operate in time critical, high-risk environments where fatalities and injuries are consistently linked to human errors (Flin et al., 2008; Shappell and Wiegmann, 1997). Their command decisions and the subsequent actions of their organisation may then be open to scrutiny during coronial proceedings, as seen recently in the United Kingdom (UK) with the Grenfell Tower Inquiry (Grenfell Tower Inquiry, 2019).

Improving the safety of emergency services personnel and importantly the communities they serve, requires the development of technical excellence and command decision-making in tandem. Decision making skills are becoming recognised as a key part of a fire commander's skill set, with fire services increasingly seeking systematic validation of those skills, as well as training or management frameworks that incorporate and value them (Butler et al., 2020; Cohen-Hatton et al., 2015a; Cohen-Hatton et al., 2015b)

Competence is the combination of training, skills, experience and knowledge that a person has acquired and their ability to apply them to perform a task safely (HSE, 2020). Other factors which can affect competence are attitude and physical ability (HSE, 2020). The specific guidance from the UK Health \& safety Executive (HSE) states 'Competence in health and safety should be an important component of workplace activities, not an add-on or afterthought'. The acquisition and demonstration of competence should therefore be considered a principle component of fire service training.

Competence or expert knowledge can be differentiated into two distinct groups: explicit knowledge and tacit knowledge. Explicit knowledge is factually based, and traditionally taught in a classroom, but is proven of little use in generating effective skill-based training or decisionmaking (Zsambok and Klein, 1997). Tacit knowledge involves a detailed understanding of how a whole system operates. It is the use of the explicit technical knowledge, through practical application, that translates into tacit knowledge or operational competence (Flin et al., 2008).

The training of these non-technical skills or Human Factors have traditionally relied on an emphasis on theoretical lecture or classroom-based tuition (Flin et al., 2008). The individuals then use this technical knowledge and develop operational competence through practical application, initially utilising traditional drill sessions then practically at incidents.

Training for effective decision-making during emergencies should include unexpected elements and unusual combinations of problems. It should require a knowledge of emergency procedures but should also empower the Incident Commander with the competence and confidence to take command and to control the situation (Crichton and Flin, 2017).

For over thirty years, studies into the use of simulation-based training (SBT) in high-hazard environments such as aviation and healthcare, (in conjunction with observation and feedback for learning and practice) has reduced the potential for human error and improved safety (Crichton, 2017). However, it has been concluded that simulation-based exercises in themselves are not enough to train the expected behaviours (Salas et al., 1998). Training strategies, learning objectives and feedback from trained and competent observers are essential in developing decision-making behaviours which mitigate human error (Salas et al., 2004). Effective training must utilise scenarios which incorporate events to stimulate the practice and demonstration of 
Systematic Incident Command training and Organisational Competency.

Knowledge, Skills and Attitudes (KSAs) (Flin 2008, Crichton 2017) which can provide the basis as feedback criteria.

The UK Incident Command Manual (NOG, 2020) states that 'Fire and rescue services should seek to validate the knowledge, skills and attributes of candidates following appropriate training, development and support for all levels of command. Operational assurance assessments to confirm competence should be carried out following suitable exposure of candidates to operational incidents'.

Carrying out validation and assessment of competence should satisfy fire and rescue services that the candidates will deliver an assertive, safe, and effective, all-hazards command to safeguard the public and operational personnel. But the question of the composition of these assessments is less clear. The specific competences to be measured, and the way they should be valued, scored, or deemed as acceptable is not defined in the guidance documents.

The Incident Command System (ICS), and how it operates within a wider framework of policies and an in-depth understanding of operational issues, is split into three functional areas (Buck et al., 2006). This basic philosophy is mirrored in all international ICSs, National Incident Management System (NIMS) from the United States (Jensen and Youngs, 2015) and Australasian Inter-service Incident Management System (AlIMS) among others (Luke, 2016). These three functional areas are:

- Command skills - considers the skills, knowledge and understanding required by an Incident Commander, and the importance of developing and maintaining such competencies

- Safety management - the principal consideration of the Incident Commander is the safety of their personnel. When developing their tactical plans, the Incident Commander must achieve an appropriate balance between the benefit of undertaking planned action and the associated risks

- Organisation at an incident - this gives the Incident Commander a recognised system from which to work, when organising and using personnel and resources at an incident

It clarifies the that the key aspects of operational deployment will require candidates to demonstrate the following competences:

- Technical skills - personnel and commanders to have the required skills, knowledge and understanding to perform their routine duties

- Command and control - to have the required skills, knowledge and understanding to perform their duties on the incident ground

- Management and leadership skills - to be able to, manage their allotted activities, prioritise, and balance the demands of the role and the ability to develop confident and resilient students

- Working with others - be able to problem- solve and deal with change in an organised, safe, and systematic way

- Multi-agency collaboration - to be able to work as part of a team and in partnership with other agencies to save life, reduce harm and safeguard communities 
Systematic Incident Command training and Organisational Competency.

The key question is how to support the students in achieving these competences, when the role of the incident command trainer is as complex as the role they are teaching and assessing. It is important to find the balance between teaching quantitative technical knowledge and giving the student opportunities to demonstrate its application qualitatively. The knowledge or recalling of facts is only a small component of learning or the demonstration of expertise. The work of Bloom in the 1950s and 1960s (Bloom, 1956), later revised by (Anderson and Krathwohl, 2001), outlined six levels of knowledge in a taxonomy or hierarchy (detailed below). Bloom's Taxonomy classified thinking according to six cognitive levels of complexity. The levels are often perceived as a stairway, with trainers encouraging their students to climb to a higher tier of thought. The taxonomy is hierarchical; in that each level is subsumed by the higher levels.

1. Remember - Retrieving, recognising, and recalling knowledge from long-term memory

2. Understanding - Constructing meaning from oral, written, and graphic messages

3. Applying - Carrying out or using a procedure through executing or implementing

4. Analysing - Breaking material into the constituent parts, determining how the parts fit together

5. Evaluating - Making judgements based on criteria and standards through checking and critiquing

6. Creating - Putting elements together to form a coherent or functional whole

When Incident Command competence is assessed through quantitative written tasks or examinations, it can be argued that this will only cover the 'Remember and Understand' tiers of Bloom's Taxonomy. In contrast, qualitative competencies are utilised when incidents present unexpected challenges which fall outside of pre-defined organisational policy or procedure. Specifically, they will need to 'create' a bespoke solution to an incident based on their operational experience and training, which is influenced by the environment and circumstances facing them.

However, the training received might only have covered the quantitative 'Remember and Understand' tiers of the hierarchy. Thus, leaving the incident risk assessment and subsequent decision making to be concluded through professional judgement or operational experience; when it has been well documented that incident numbers are falling (Knight 2013, Home Office, 2019), thus leaving Incident Commanders ill-equipped to make such decisions.

Effective Incident Commanders are required to retain knowledge on organisational culture, doctrine, policy and procedural framework; and their appropriate application at any incident (Brunacini, 2002). However, the most critical factor is the ability of Incident Commanders to make and execute decisions under time and consequential pressure (Hutton and Klein, 1999).

The training and assessment of these qualitative skills (sometimes called non-technical skills or behavioural markers) within high-reliability industries are well-documented (Crichton 2017). Klampfer et al describe behavioural markers as 'observable, non-technical behaviours that contribute to a superior or substandard performance within a work environment' (Klampfer et al., 2001).

\section{Effective Command Behavioural Marker Framework}


Systematic Incident Command training and Organisational Competency.

Effective Command was created as a behavioural marker framework in 2015 by two academic/fire service practitioners (UK and Australia), to address the disconnect between academic research and its application within the Fire Service. The aim was to develop a robust strategy to implement non-technical skills during Fire-officer training. It focuses on five key behaviours: Situational Awareness, Decision-making, Objective setting, Action behaviours and Review as identified by Launder and Perry (2014). These five key behaviours were then subdivided to form eight sections in the framework as detailed below in Table 1:

\section{Effective Command Methodology}

The Effective Command training methodology aligns with the five principles of simulation-based exercise team training, as outlined by Crichton (2017).

- Principle 1 - Develop learning objectives and expected performance standards

Using scenarios, as outlined by Sarna (2002), Incident Commanders are presented with unexpected events or dilemmas (Lamb, 2014). These cues stimulate the expected behaviours and allow relevant behavioural markers to be practiced or demonstrated.

- Principle 2 - Train the team or individuals

Training the individual in non-technical skills is often overlooked during training and development of Fire Officers

- Principle 3 - Use a structured observation tool

The structured observation tool Effective Command is used to capture positive behaviours and those requiring improvement. The framework is also used as a basis of the training design used to provide feedback, and for self-reflection by the student.

- Principle 4 - Provide feedback during a structured debrief.

Feedback is given face-to-face immediately following a scenario-based exercise, and behaviours observed during the exercise are highlighted.

- Principle 5 - Repeat the training regularly

Organisations are advised to embed the use of the Effective Command framework in onstation drills, live incident monitoring, large scale practical exercises and ongoing incident command training and assessments; to continually train against the behavioural markers identified. 
Systematic Incident Command training and Organisational Competency.

\section{Applications of Effective Command}

The Effective Command tool collates data using 3 different applications: Training, Incident Monitoring and Formal Assessment.

\section{Training}

The participants completed self-reflective Effective Command reports following their completion of structured training. The participants received minimal training on how to use the tools. There was no standardisation of the assessment measures, as such this data is only indicative of the completion of the training rather than being deemed suitable for in-depth analysis.

\section{Incident Monitoring}

The participants within this group are all operational commanders who fulfil an incident monitoring role for their organisation. These monitoring officers were trained and standardised internally by their organisation, so there was an organisational consistency in 'what good looks like'. However, this consistency was not present between different organisations.

\section{Formal Assessments}

As per the guidance document by Klampfer et al. (2001), all assessors were sector competent and received training in non-technical skills and the use of the Effective Command behavioural marker framework. These assessors were re-validated annually.

\section{Effective Command Framework}

The Effective Command framework (Effective Command, 2020) is aligned to UK National Fire Service competency role-maps and directly accredited by appropriate sector-specific awarding bodies (NOG, 2020). It is routinely used in both development and assessment of Fire Officers in the UK as well as in nine countries worldwide. Participants are scored in eight sections: each containing nine criteria (behavioural markers/technical competencies). There are five possible marks for each criterion, with a maximum score of forty-five achievable in each section, these are the guidance parameters.

5/5 - Exceeding the expected behaviours of the role, continued professional development required to maintain.

$3 / 5$ - Satisfactory behaviours of the role demonstrated, continued professional development required to improve.

$1 / 5$ - Showing little or few of the expected behaviours, safety critical, significant development needed to reach a satisfactory level.

The rationale for the key behaviours are explored through discussions between the candidate and the assessor. The specific behaviours required for each criterion is importantly not specified by the Effective Command framework, instead each organisational user must set the 
Systematic Incident Command training and Organisational Competency.

parameters for 'what good looks like' themselves. Organisational culture, Fire Service topography and employee demographics (full-time, part-time and volunteers) will all affect the expectations and the competence acceptability profile. The overall aim is to achieve Assertive, Effective \& Safe Incident Commanders (NOG, 2020) irrespective of incident type, the Effective Command tool permits that flexibility through its application.

A percentage score was calculated for each section and the results were categorised using a traffic light system where Red shows a score of $55.5 \%$, Amber 55.5-70\% and Green > 70\%. These grade boundaries were selected based on expert opinion and organisational expectations. The overall assessment score is calculated according to the following rules:

\section{Red Result - Unsatisfactory}

If two safety critical failings (separate criteria scores of $1 / 5$ ) were recorded in a single section, the candidate will fail the whole section. If 2 or more whole sections (1-8) were scored as red, then that will be an automatic fail of the whole assessment.

\section{Amber Result - Satisfactory}

If one section was recorded as red, regardless of the scores of the other sections the overall assessment result will be amber. An amber result could also be achieved if the number of the overall section scores does not exceed four green results.

\section{Green Result - Exceeded Expectations}

Where five or more overall sections are scored as green, but no one section was scored as red.

\section{Data Collection}

During this study 169,657 separate criterion results (formal assessment, incident monitoring and training) were downloaded and processed in Microsoft Excel (Microsoft Corporation, 2018), using standard descriptive statistical methods. A multivariate ANOVA test was performed using MS Excel to determine any significant statistical relationship between command level and mean score across the eight main sections. No significant relationship was found $(p=0.567, \mathrm{Cl}=0.074)$, and so it was concluded that no further statistical investigation was required. A possible reason for no statistical significance was due to the small sample size for $L 3$ and $L 4$, as visually there is a notable difference in responses, especially at $L 4$.

The dataset included data from fire services in the UK, Portugal, France, Italy, Estonia, Dubai, Singapore, Australia, and Canada. The services themselves represented wholetime and on-call (UK, Europe \& Middle East) firefighters, volunteers (Canada and Australia), rural, urban and aviation fire departments (Singapore \& Australia). The rank of the candidate, type and level of assessment, the score reached and the colour coding of that score was included.

This study has focused on data generated from the formal assessments only. 1261 formal assessments were completed between January 2017 and May 2019. These encompass over 
Systematic Incident Command training and Organisational Competency.

90,000 separate data entries at command levels L1-4 (NOG, 2020), and were recorded by accredited and annually verified assessors.

- Level 1 - Operational (in command of 1-3 Appliances)

- Level 2 - Operational (in command of 4-6 Appliances)

- Level 3 - Tactical (in command of 6-10 Appliances)

- Level 4 - Strategic (in command of $11+$ Appliances). 
Systematic Incident Command training and Organisational Competency.

\section{Results}

Of the 1261 completed formal assessments analysed, 994 were L1 commanders, 208 at L2, 42 at L3 and 17 at L4. Whilst no significant statistical relationship was found through the statistical analysis (possibly due to the relatively small sample size for $\mathrm{L} 3$ and $\mathrm{L} 4$ officers), some differences can be observed, and we have used these observations to inform our interpretation of the data.

When we examine all data from the L1-4 formal assessments, approximately ten percent of participants failed to meet the minimum standard required to pass the assessment. Those that met the satisfactory minimum standard, were further broken down into Amber $53 \%$ (satisfactory) and Green 37\% (exceeded expectations) groups.

Further analysis at each command level highlights a fluctuation in failure rates (Fig. 1). The highest rate of failures was during the assessment of L2 Officers, $11.1 \%$. Whereas failures of L3 and $L 4$ officers were $4.8 \%$ and $5.9 \%$ respectively. $L 4$ officers were more likely to achieve a Green assessment outcome (exceed expectations) than the other levels of officers.

When specific strengths and weaknesses at each level are examined across all assessment sections, the L2 officers appeared to perform the worst - with only $2.6 \%$ deviation between the highest and lowest scores across all assessment sections.

While the L1, 2 and 3 officers showed strengths at the Information Gathering phase (section 1), the same officers were scored as less able during the Information Evaluation phase (section 3). The review phase (section 8) was another area of weakness for the L2 and L3 officers. There is an increase in mean score as Command Level increases (Fig. 2). Further analysis of a larger dataset will be needed before any significant conclusions can be made.

L4 officers scored, on average, ten percent (range 9.1-12.1\%) higher than officers at the other levels, across all the sections, $82.4 \%$ of all L4 officer assessments achieved a green 'exceeds expectations' outcome.

The data can be further analysed to examine specific criteria or behavioural markers responsible for the assessment results. Table 2 shows the strengths and weaknesses identified from the L1 assessments. There is a clear identification of key behavioural markers with several criteria determined as strengths in individuals who achieve satisfactory assessment outcomes, and as weaknesses in those individuals who fail to meet the required standard. The frequency of the criteria scores were recorded in either 1/5- 2/5 (Red score) or 3/5-5/5 (Amber/Green score). These behavioural markers were then sorted, highest to lowest. The highlighted cells appear on both the Strengths \& Weaknesses list. These key behavioural markers can strongly influence the outcome of an incident command assessment.

The data presented in Table 2 shows the strengths and weaknesses in behaviours of L2 Officers. This data set is more varied, with only one assessment criteria found on both lists. This behaviour focuses on appropriate decision-making strategy being used to resolve the incident.

At L3-4, the numbers were significantly smaller (Red Score L3 $n=2, L 4 n=1$ ), and so no clear trend could be confidently extracted. 
Systematic Incident Command training and Organisational Competency.

\section{Discussion}

This study suggests that structured analysis of incident command assessment should inform subsequent training cycles, not only of individuals but of organisations and organisational procedures. The competence profile (breakdown of individuals classified as red, amber or green) presented in Fig. 1 is representative of every organisation involved in this study, suggesting that the demographics could be a fixed variable reflecting the ever-changing workforce due to promotions, retirements and new roles being created. Further study over subsequent years, where organisations are developing their personnel utilising this methodology, will enable us to determine: If training were focussed on the areas identified in Table 2 would this significantly alter the organisational command competence profile?

For Incident command training and assessment to be delivered at the higher end of Bloom's Taxonomy, there will always be some level of subjectivity and therefore some variation or range in results. The development of tacit knowledge in line with the incident command competencies identified within the UK Incident Command manual will always be open to some local interpretation, and to some extent local circumstances. However, assessor training and standardisation will minimise that variation. Standardising 'what good looks like' will enable service-to-service comparisons in competence profiles and training methodologies, whilst accommodating localisms around response mobilising and procedures.

One notable result, seen in Fig. 2 , is the dip in overall competence scores between L1 and L2 officers. This could partly be explained by the processes involved in fire service career progression. In the UK, L1 officers (Crew Manager, Watch Manager A\&B) typically work as a part of a team, which has positive benefits in terms of confidence, collaboration, and sanity-checking at an incident.

L2 officers respond to incidents individually and are much more isolated as Incident Commanders than their L1 counterparts. The development process to become a L2 officer is also typically rapid, compared to the gradual training and mentoring that occurs in the development of L1 officers, and $L 2$ officers may well find themselves quickly out of their comfort zone.

The data presented in this study provides a strong argument for a more supported development process for L2 officers, enabling them to grow into the role and competently manage the incident.

In addition, there is a gradual improvement in officer competence from L2-4 officers. The individual competence scores increase gradually with progression through the ranks, suggesting that individuals are growing in both confidence and competence. This observation correlates with that of Canon-Bowers and Bell (1997) who identified the characteristics and mechanisms of an effective decision maker, and how experienced decision makers differ from that of a novice (Canon-Bowers and Bell, 1997). They suggest that expert decision makers can perform incident evaluation more quickly and accurately than novices. Two recognised aspects of this incident evaluation are cue and pattern recognition. Experts are better and faster at identifying the relevant cues, the significance of them, and the patterns that they form (Sinclair et al., 2012). 
Systematic Incident Command training and Organisational Competency.

This observation is evident in the data presented in Fig. 2, where the individuals have developed their evaluation skills, and this is reflected in the improvement in organisational competence profile.

One consideration is that current $\mathbf{L} 4$ officers developed their command skills during a time when there were considerably more incidents and their operational exposure was very high (Knight, 2013). Future work should follow these competence profiles over the next 10 years, as the incident exposure of all commanders is likely to reduce and, in many cases, have been replaced with simulation-based training.

The analysis of the specific strengths and weaknesses in L1 commanders identified in Table 2 has identified six key behaviours, which when achieved well, can alter the overall assessment outcome from red to an amber/green result.

This study suggests that improvements in areas of information comprehension and evaluation would have a big impact on the outcomes of these assessments. It is of note that learning objectives in analytical and evaluation skills are found towards the top of Bloom's Taxonomy. This suggests that higher incident or scenario exposure, with metacognitive understanding of the decision rationale (Lamb 2014) could reverse these weaknesses and turn them into individual strengths.

Decision-making is both a key strength and weakness of L2 officers and requires further exploration. Typically, experienced L1 officers rely on recognition-primed decision making (RPD), to resolve their incidents enabling them to rapidly evaluate a situation and decide on the appropriate course of action in high-pressure situations (Zsambok and Klein, 1997, Hutton and Klein, 1999, Klein, 2008). Tactical (L2) and Strategic officers (L3 - 4), will more frequently make slower time analytical decisions, as the incident phase is less dynamic. Further exploration of this skills gap of inexperienced L2 officers could provide further insight, but also solutions to address this competence deficit.

In addition, further studies specifically investigating these strength and weakness key areas during the L1 and L2 Incident Commander development are required. Through using this data, an organisation can invoke double loop learning, enabling them to change training mechanisms or philosophies to support more effective Incident Commander development.

\section{Summary}

Structured and holistic training and assessment systems, like Effective Command, provide a safe and efficient way of developing and assessing the competence of Incident Commanders. By analysing the data generated, identified areas of strength or weakness can be fed into subsequent training cycles, to maximise continual organisational development of their personnel. By employing a consistent behavioural framework, the process of developing essential knowledge and decision-making behaviours begins earlier and ensures firefighters are safer and more effective, both immediately and as future officers. The behaviours examined through this study have been identified as critical in academic literature, Coronial Reviews and Royal Commissions. The development of these behaviours will significantly enhance the safety of operational personnel, the public and importantly can be used as evidence that an 
Systematic Incident Command training and Organisational Competency.

organisation has learned from and addressed known risks to firefighters. A long-term study to investigate the impact and effectiveness of the Effective Command training system and its influence on improving the organisational competency profile, through the identification, training, and assessment of key behavioural markers, should be considered. 
Systematic Incident Command training and Organisational Competency.

\section{References}

Anderson, L.W., Krathwohl, D.R. (Eds.), 2001. A taxonomy for learning, teaching, and assessing: a revision of Bloom's taxonomy of educational objectives, Complete ed. ed. Longman, New York.

Bloom, B.S., 1956. Taxonomy of educational objectives: the classification of educational goals Handbook I, Handbook I, McKay; Longman, New York; New York; London.

Brunacini, A., 2002. Incident Command Functions, in: Incident Command: Tales from the Hot Seat. Routledge. https://doi.org/10.4324/9781315252483

Buck, D.A., Trainor, J.E., Aguirre, B.E., 2006. A Critical Evaluation of the Incident Command System and NIMS. Journal of Homeland Security and Emergency Management 3. https://doi.org/10.2202/1547-7355.1252

Butler, P.C., Honey, R.C., Cohen-Hatton, S.R., 2020. Development of a behavioural marker system for incident command in the UK fire and rescue service: THINCS. Cogn Tech Work 22, 1-12. https://doi.org/10.1007/s10111-019-00539-6

Canon-Bowers, J.A., Bell, H.H., 1997. Training Decision Makers for Complex Environments: Implications of the Naturalistic Decision-Making Perspective. NAVAL AIR WARFARE CENTER TRAINING SYSTEMS DIV ORLANDO FL.

Cohen-Hatton, S.R., Butler, P.C., Honey, R.C., 2015a. An Investigation of Operational Decision Making in Situ: Incident Command in the U.K. Fire and Rescue Service. Hum Factors 57, 793-804. https://doi.org/10.1177/0018720815578266

Cohen-Hatton, S. R., \& Honey, R. C., 2015b. Goal-oriented training affects decision-making processes in virtual and simulated fire and rescue environments. Journal of Experimental Psychology: Applied, 21(4), 395-406. http://dx.doi.org/10.1037/xap0000061

Crichton, M., Flin, R., 2017. Command Decision Making, in: Incident Command: Tales from the Hot Seat. Routledge. https://doi.org/10.4324/9781315252483

Crichton, M.T., 2017. From cockpit to operating theatre to drilling rig floor: five principles for improving safety using simulator-based exercises to enhance team cognition. Cogn Tech Work 19, 73-84. https://doi.org/10.1007/s10111-016-0396-9

Deeming, H., 2018. The Kerslake Report: An independent review into the preparedness for, and emergency response to, the Manchester Arena attack on 22nd May 2017.

Effective Command. 2020. Effective Command. [ONLINE] Available at: https://www.effectivecommand.org/. [Accessed 19 August 2020].

FBU, 2015. The future of the fire and rescue service. Executive council policy statement. Fire Brigades Union.

Flin, R., O'Connor, P., Crichton, M., 2008. Safety at the Sharp end - A guide to Non-technical Skills. CRC Press.

Grenfell Tower Inquiry, 2019. Phase 1 Report: Report of the Public Inquiry into the fire at Grenfell Tower on 14 June 2017.

Home Office, 2019. Fire and rescue incident statistics: England, year ending March 2019. Statistical Bulletin.

HSE, 2020. What is Competence? - Competence in health and safety [WWW Document]. URL https://www.hse.gov.uk/competence/what-is-competence.htm (accessed 4.17.20).

Hutton R.J., Klein G., 1999. Expert decision-making. Systems Engineering 2, 32-45. https://doi.org/10.1002/(SICI)1520-6858(1999)2:1<32::AID-SYS3>3.0.CO;2-P

Jensen, J., Youngs, G., 2015. Explaining implementation behaviour of the National Incident Management System (NIMS). DISASTERS. https://doi.org/10.1111/disa.12103 
Systematic Incident Command training and Organisational Competency.

Klampfer, B., Flin, R., Helmreich, R., Husler, R., Sexton, B., Field, P., Staender, S., Dieckmann, P., Amacher, A., 2001. Enhancing performance in high risk environments:

Recommendations for the use of Behavioural Markers. Report from the behavioural markers workshop, Zurich, 5-6 July. Daimler Benz Foundation.

Klein, G., 2008. Naturalistic Decision Making. Hum Factors 50, 456-460. https://doi.org/10.1518/001872008X288385

Knight, S.K., 2013. Facing the Future findings from the review of efficiencies and operations in fire and rescue authorities in England. TSO., London.

Lamb, K. J., Davies, J., Bowley, R., and Williams, J-P. (2014). "Incident command training: the introspect model". International Journal of Emergency Services, Vol. 3, No 2, pp131-143. https://doi.org/10.1108/IJES-09-2013-0023

Launder, D. and Perry, C. (2014), "A study identifying factors influencing decision making in dynamic emergencies like urban fire and rescue settings", International Journal of Emergency Services, Vol. 3 No. 2, pp. 144-161, available at: http//dx.doi.org/10.1108/IJES-06-2013-0016

Luke, S., 2016. AlIMS Health check. Australian Journal of Emergency Management, 31, 15-20.

National Operational Guidance. 2020. Incident Command. [ONLINE] Available at: https://www.ukfrs.com/guidance/incident-command. [Accessed 18 August 2020].

Salas, E., Bowers, C.A., Rhodenizer, L., 1998. It Is Not How Much You Have but How You Use It: Toward a Rational Use of Simulation to Support Aviation Training. The International Journal of Aviation Psychology 8, 197-208. https://doi.org/10.1207/s15327108ijap0803_2

Salas, E., Burke, C., Stagl, K., 2004. Developing teams and team leaders: strategies and principles, in: Leader Development for Transforming Organizations: Growing Leaders for Tomorrow. Lawrence Erlbaum Associates, Mahwah, N.J., pp. 325-358.

Sarna, P., 2002. Managing the spike: The command perspective in critical incidents. In: Incident Command: Tales from the Hot Seat. Routledge. https://doi.org/10.4324/9781315252483

Shappell, S.A., Wiegmann, D.A., 1997. A Human Error Approach to Accident Investigation: The Taxonomy of Unsafe Operations. The International Journal of Aviation Psychology 7, 269-291. https://doi.org/10.1207/s15327108ijap0704_2

Sinclair, H., Doyle, E.E.H., Johnston, D.M., Paton, D., 2012. Decision-making training in local government emergency management. Intl Jnl of Emergency Services 1, 159-174. https://doi.org/10.1108/20470891211275939

Zsambok, C. E., \& Klein, G. (Eds.). (1997). Expertise: Research and applications. In: Naturalistic decision making. Lawrence Erlbaum Associates, Inc 
Table 1

\begin{tabular}{|c|c|}
\hline Assessment Sections & Behavioural markers and Technical competencies areas \\
\hline $\begin{array}{l}\text { 1. Information } \\
\text { Gathering }\end{array}$ & $\begin{array}{l}\text { The gathering of information from personnel handovers, } \\
\text { briefings, multi-agency liaison, weather conditions, visual cues, } \\
\text { and radio communication (Endsley 2000). }\end{array}$ \\
\hline 2. Comprehension & The understanding of the information gathered. \\
\hline 3. Evaluation & $\begin{array}{l}\text { The evaluation of the incident, the anticipated speed of its } \\
\text { progression and any likely impact resulting from the incident } \\
\text { development or reduction. }\end{array}$ \\
\hline 4. Decision-Making & $\begin{array}{l}\text { The methods by which the decisions were made, using } \\
\text { procedures, the utilisation of other agencies, the role and } \\
\text { management of the media, and the validity of the decisions } \\
\text { made. }\end{array}$ \\
\hline 5. Plan & $\begin{array}{l}\text { The setting of appropriate incident objectives, which } \\
\text { considered suitability, feasibility, and acceptability. }\end{array}$ \\
\hline 6. Communication & $\begin{array}{l}\text { Accurate communication maintained throughout the incident, } \\
\text { which kept all relevant and multi-agency partners informed. }\end{array}$ \\
\hline 7. Command & $\begin{array}{l}\text { the effective command of the whole incident, including the } \\
\text { delegation of responsibilities for any necessary functions and } \\
\text { investigations. }\end{array}$ \\
\hline 8. Review & $\begin{array}{l}\text { Continually review incident progress against objectives, } \\
\text { including the long-term effects of the incident on the } \\
\text { organisation. }\end{array}$ \\
\hline
\end{tabular}


Figure 1

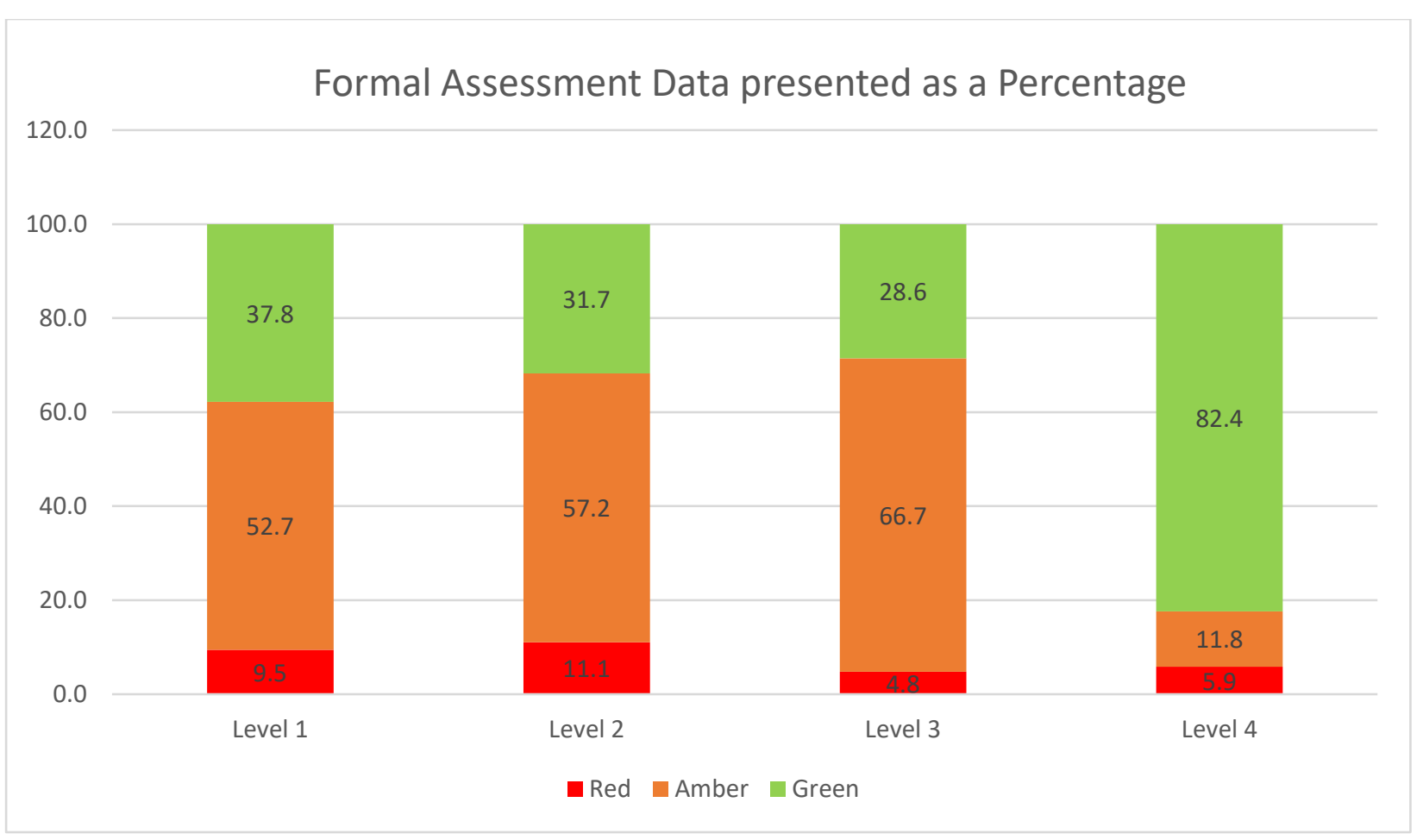

26 
Figure Two

Average Scores for Assessment Sections

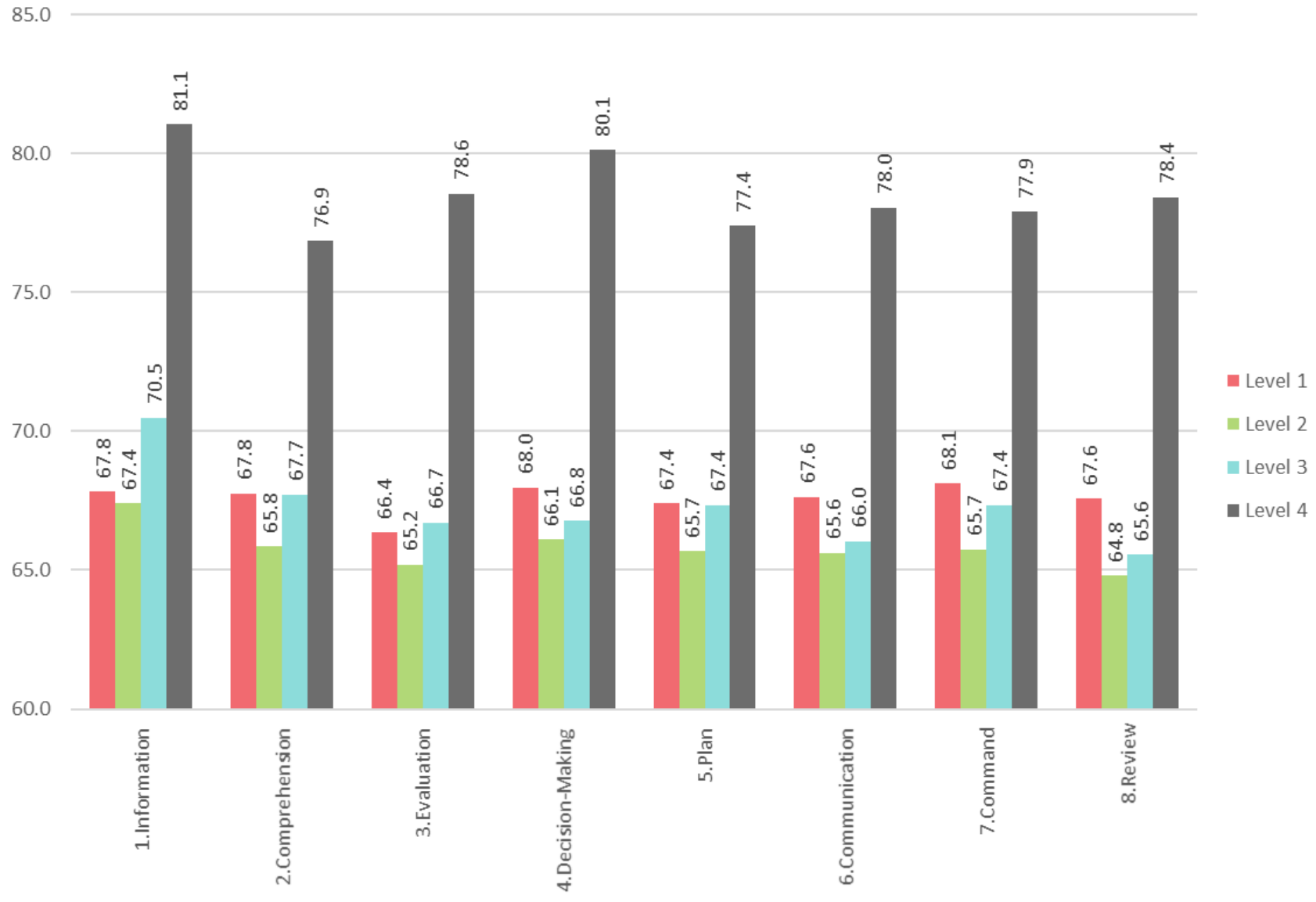


Table Two

\begin{tabular}{|c|c|c|c|}
\hline \multicolumn{2}{|c|}{ Strengths } & \multicolumn{2}{|c|}{ Weaknesses } \\
\hline Section & Assessment Criteria & Section & Assessment Criteria \\
\hline 1. Information & $\begin{array}{l}\text { Collection of initial information } \\
\text { using relevant channels }\end{array}$ & 3.Evaluation & $\begin{array}{l}\text { Identified and understood } \\
\text { implications of key risks and } \\
\text { hazards }\end{array}$ \\
\hline 7. Command & Effective prioritisation of tasks & 5. Plan & $\begin{array}{l}\text { Appropriate resources to } \\
\text { meet the needs of the } \\
\text { incident }\end{array}$ \\
\hline 8. Review & $\begin{array}{l}\text { Modifications or introductions } \\
\text { of changes, to incident plan }\end{array}$ & 1.Information & $\begin{array}{l}\text { Building } \\
\text { layout/documentation }\end{array}$ \\
\hline 2. Comprehension & $\begin{array}{l}\text { Risk assessment/understanding } \\
\text { and safe systems of work } \\
\text { utilised }\end{array}$ & 5. Plan & $\begin{array}{l}\text { Develop \& implement risk } \\
\text { control/contingency } \\
\text { measures and utilise safe } \\
\text { systems of work }\end{array}$ \\
\hline 3.Evaluation & $\begin{array}{l}\text { Identified appropriate } \\
\text { situational cues and } \\
\text { information }\end{array}$ & 3. Evaluation & $\begin{array}{l}\text { Was able to source and } \\
\text { interpret key cues in a timely } \\
\text { manner }\end{array}$ \\
\hline 2. Comprehension & $\begin{array}{l}\text { Suitability/sufficiency of } \\
\text { resources }\end{array}$ & 4.Decision-making & $\begin{array}{l}\text { Decision involves - accurate } \\
\text { situational awareness of } \\
\text { hazards and risks present }\end{array}$ \\
\hline 2. Comprehension & $\begin{array}{l}\text { Evolution/rate of incident } \\
\text { change }\end{array}$ & 7. Command & $\begin{array}{l}\text { Appropriate incident } \\
\text { structure }\end{array}$ \\
\hline 3. Evaluation & $\begin{array}{l}\text { Was able to source and } \\
\text { interpret key cues in a timely } \\
\text { manner }\end{array}$ & 2.Comprehension & $\begin{array}{l}\text { Evolution/rate of incident } \\
\text { change }\end{array}$ \\
\hline 4.Decision-making & $\begin{array}{l}\text { Decision involves - accurate } \\
\text { situational awareness of } \\
\text { hazards and risks present }\end{array}$ & 2. Comprehension & $\begin{array}{l}\text { Suitability/sufficiency of } \\
\text { resources }\end{array}$ \\
\hline 5.Plan & $\begin{array}{l}\text { Develop \& implement risk } \\
\text { control/contingency measures } \\
\text { and utilise safe systems of work }\end{array}$ & 3.Evaluation & $\begin{array}{l}\text { Identified appropriate } \\
\text { situational cues and } \\
\text { information }\end{array}$ \\
\hline 4.Decision-making & $\begin{array}{l}\text { Appropriate decision -making } \\
\text { and decision -control process } \\
\text { utilised }\end{array}$ & 4.Decision-making & $\begin{array}{l}\text { Appropriate decision - } \\
\text { making and decision -control } \\
\text { process utilised }\end{array}$ \\
\hline 6.Communications & $\begin{array}{l}\text { Effective communication with } \\
\text { all }\end{array}$ & 6.Communications & $\begin{array}{l}\text { Effective communication of } \\
\text { overall plan, where } \\
\text { appropriate, with other } \\
\text { Multi-Agency commanders }\end{array}$ \\
\hline 8. Review & $\begin{array}{l}\text { Collate relevant points for the } \\
\text { debrief or possible } \\
\text { investigation }\end{array}$ & 2.Comprehension & $\begin{array}{l}\text { Safety briefs, where } \\
\text { appropriate, with other } \\
\text { Multi-Agency commanders }\end{array}$ \\
\hline 3.Evaluation & $\begin{array}{l}\text { Able to predict progression of } \\
\text { key risks and hazards }\end{array}$ & 4.Decision-making & Decisions are timely \\
\hline 5.Plan & $\begin{array}{l}\text { Develop \& implement risk } \\
\text { control/contingency measures } \\
\text { and utilise safe systems of work }\end{array}$ & 3.Evaluation & $\begin{array}{l}\text { Considered wider incident } \\
\text { implications - cover moves, } \\
\text { road closures, early joint } \\
\text { media strategy }\end{array}$ \\
\hline 7.Command & Effective prioritisation of tasks & 6.Communications & $\begin{array}{l}\text { Establish an effective } \\
\text { communication plan }\end{array}$ \\
\hline 6.Communications & Incident Handover & 2.Comprehension & $\begin{array}{l}\text { Risk assessment/ } \\
\text { understanding and safe } \\
\text { systems of work utilised }\end{array}$ \\
\hline 7.Command & Delegation of tasks/sectors & 5.Plan & Develop appropriate tactics \\
\hline 4.Decision-making & $\begin{array}{l}\text { Decision involves - accurate } \\
\text { situational awareness of } \\
\text { hazards and risks present }\end{array}$ & 5.Plan & $\begin{array}{l}\text { Strategies developed that } \\
\text { are aligned to objectives, } \\
\text { consider a joint Multi- } \\
\text { Agency working strategy }\end{array}$ \\
\hline 5.Plan & $\begin{array}{l}\text { Appropriate FRS resources to } \\
\text { meet the needs of the incident }\end{array}$ & 8.Review & $\begin{array}{l}\text { Reviewed the effectiveness } \\
\text { of current strategy and } \\
\text { tactics }\end{array}$ \\
\hline
\end{tabular}

